\title{
INSERÇÃO DE AÇÕES DE SAÚDE BUCAL E LEVANTAMENTO EPIDEMIOLÓGICO JUNTO À PASTORAL DA CRIANÇA DOS MUNICÍPIOS DE SARANDI E MANDAGUARI-PR.
}

Ana Paula BONOTTO, Alessandro Rafael BLENK, Juliana Yuri NAGATA, Thaís Aglaet Mattos MIRANDA, Mirian Marubayashi HIDALGO

Para proporcionar saúde às crianças assistidas pela Pastoral da criança de Mandaguari e Sarandi-PR, o grupo PET-Odontologia-UEM, junto aos líderes comunitários, busca há oito anos integrar ações promotoras de saúde bucal às de saúde geral. Este trabalho visa apresentar a inserção dessas ações e o levantamento epidemiológico de saúde bucal realizado em 2007 nessas comunidades. As atividades educativas são desenvolvidas com as crianças e familiares, mensalmente, no Dia da Vida e também com os líderes, capacitados para atuarem como multiplicadores das informações básicas de saúde bucal. Consistiram de fantoches, músicas, brincadeiras, vídeos, escovação supervisionada, palestras e demonstração em macro modelos. O levantamento epidemiológico foi realizado nas crianças de 0 a 12 anos utilizando o critério de cores: vermelho, azul e verde e naquelas de 4 a 12 anos, também o índice de CPO-D. Em Sarandi $(n=60)$, o índice foi de 2,9 na faixa etária de 4-6 anos, 3,8 de 7-9 e 4, de 10-12. Em Mandaguari ( $n=98)$, obteve-se 2,9 entre 4-6 anos, 1,7 de 7-9 e 3,6 de 10-12. Conclui-se que a saúde bucal das crianças assistidas é satisfatória, mas há possibilidade de melhorias em especial em Sarandi-PR se os esforços forem concentrados na conscientização de sua importância.

Palavras-chave: Epidemiológico; Odontologia; Saúde Bucal. 